\title{
Increased Standardised Incidence Ratio of Malignant Pleural Mesothelioma in Taiwanese Asbestos Workers: A 29-Year Retrospective Cohort Study
}

\author{
Cheng-Kuan Lin, ${ }^{1}$ Yu-Ying Chang, ${ }^{2}$ Jung-Der Wang, ${ }^{1,3}$ and Lukas Jyuhn-Hsiarn Lee, ${ }^{2,4,5}$ \\ ${ }^{1}$ Department of Public Health, College of Medicine, National Cheng Kung University, Tainan 70101, Taiwan \\ ${ }^{2}$ Division of Environmental Health and Occupational Medicine, National Health Research Institutes, 35 Keyan Road, \\ Zhunan, Miaoli County 35053, Taiwan \\ ${ }^{3}$ Departments of Internal Medicine, Occupational and Environmental Medicine, National Cheng Kung University Hospital, \\ Tainan 70403, Taiwan \\ ${ }^{4}$ Department of Environmental and Occupational Medicine, National Taiwan University Hospital, Taipei 10002, Taiwan \\ ${ }^{5}$ Institute of Occupational Medicine and Industrial Hygiene, College of Public Health, National Taiwan University, \\ Taipei 10020, Taiwan
}

Correspondence should be addressed to Lukas Jyuhn-Hsiarn Lee; lukasneuro@gmail.com

Received 12 July 2014; Accepted 19 October 2014

Academic Editor: Shih-Bin Su

Copyright (C) 2015 Cheng-Kuan Lin et al. This is an open access article distributed under the Creative Commons Attribution License, which permits unrestricted use, distribution, and reproduction in any medium, provided the original work is properly cited.

Objective. This paper aimed to determine the standardised incidence ratio (SIR) of malignant pleural mesothelioma (MPM) in workers exposed to asbestos in Taiwan. Methods. All workers employed in asbestos-related factories and registered by the Bureau of Labour Insurance between 1 March, 1950, and 31 December, 1989, were included in the study and were followed from 1 January, 1980, through 31 December, 2009. Incident cases of all cancers, including MPM (ICD-9 code: 163), were obtained from the Taiwan Cancer Registry. SIRs were calculated based on comparison with the incidence rate of the general population of Taiwan and adjusted for age, calendar period, sex, and duration of employment. Results. The highest SIR of MPM was found for male workers first employed before 1979, with a time since first employment more than 30 years (SIR 4.52, 95\% CI: 2.25-8.09). After consideration of duration of employment, the SIR for male MPM was 5.78 (95\% CI: 1.19-16.89) for the workers employed for more than 20 years in asbestos-related factories. Conclusions. This study corroborates the association between occupational asbestos exposure and MPM. The highest risk of MPM was found among male asbestos workers employed before 1979 and working for more than 20 years in asbestos-related factories.

\section{Introduction}

Asbestos is the collective name for a group of fibrous silicate minerals that are widely used in many industries due to their strength and fire-resistant properties [1]. Asbestos can be divided into serpentine (chrysotile) and amphibole, with exposure to different types associated with different degrees of health risk. Chrysotile accounts for $95 \%$ of the asbestos in use around the world and is the only type of asbestos in commercial use today [2]. All forms of asbestos cause malignant mesothelioma and lung, laryngeal, and ovarian cancers and may cause gastrointestinal and other cancers [3].

All forms of asbestos have been classified as carcinogens by the World Health Organization (WHO) [4] and as group I human carcinogens by the International Agency for Research on Cancer (IARC) [5]. The WHO recently estimated that 125 million people globally are exposed to asbestos in the workplace, and about 107,000 people die each year from asbestos-related diseases resulting from occupational exposure [6]. Asbestos-related diseases include benign lesions of asbestosis, pleural effusion, pleural plaques, diffuse pleural 
thickening, and malignancies of the lung, peritoneum, and pleura [7]. Malignant mesothelioma (MM) is the primary malignant neoplasm arising from the serosal membranes (mesothelium), the protective linings that cover many of the body's internal organs [8], and the pleura is the most frequent site, also termed as malignant pleural mesothelioma (MPM) [9]. The association between MPM and asbestos exposure was observed by Wagner et al. in 1960 [10]. MM is a fatal disease with a median survival of approximately nine months, and it occurs with a long latency of 20-40 years after exposure to asbestos. It has been estimated that the population attributable fraction of MM among men from occupational exposure to asbestos is approximately more than $80 \%$ [11].

A few studies focusing on cancer risk among asbestosexposed workers in some specific industries in Taiwan were recently published. Yang et al. observed an increased risk of lung cancer mortality in Fengtian, a village in eastern Taiwan. Most of the residents were involved in jade processing industries from 1970 until 1980, and the current exposure level to airborne asbestos in rough grinding was up to 4.7 fibres $/ \mathrm{mL}$. The risk of lung cancer was increased with a standardised mortality ratio (SMR) of 1.28 (95\% CI 1.12 to 1.45$)$ [12]. In southern Taiwan, workers in shipbreaking industry were thought to be heavily exposed to many possible respiratory carcinogens, including welding fumes, paints, and asbestos [13]. Wu et al. conducted retrospective cohort studies over 4,000 male workers, collected from the Kaohsiung Shipbreaking Worker Union to examine mortality and cancer incidence. Elevated risk of all cancer, oral cancer, and lung cancer was documented among male shipbreaking workers. The flame cutters had highest risk of lung cancer, and one deceased man in this occupation died of pleural cancer [14] younger than 40 years, and two cases of mesothelioma were found by linkage with Taiwan's health insurance database and Taiwan Cancer Registry $[15,16]$.

The Environmental Protection Administration of Taiwan (Taiwan EPA) promulgated the Toxic Chemical Substances Control Act in 1986, with asbestos being regulated as a hazardous material in 1989 and placed under increasingly stricter controls thereafter. The majority of asbestos used in Taiwan was imported, with the amount rising significantly in the mid-1970s and peaking at 35,000 tons per year in the mid1980 s and then falling significantly in the early 1990s due to new regulations. Less than 5000 tons per year were imported by 2001 [17], and the use of asbestos in construction materials was banned in 2008. On 2 February, 2012, the Taiwan EPA announced the following schedule for a total asbestos ban: from August 1, 2012, the use of asbestos was prohibited for the manufacturing of extruded cement composite hollow panels and construction sealants; from February 1, 2013, the manufacture of asbestos roof tiles was prohibited; and from July 1, 2018, the use of asbestos in the manufacture of brake linings will be prohibited [18].

To the best of the authors' knowledge, the risks of contracting asbestos-related cancers among Taiwanese workers employed in the asbestos factories registered by labour insurance have not yet been documented. This paper thus aimed to determine the SIR of malignant pleural mesothelioma among workers potentially exposed to asbestos from workplace in Taiwan.

\section{Materials and Methods}

2.1. Establishment of the Study Cohort. This research was approved by the Institutional Review Board of National Cheng Kung University Hospital (IRB number B-ER-102162). A total of 389 asbestos-related factories were registered and categorized into seven groups by the Taiwan EPA to produce a roster profile of asbestos-related institutions. The roster profile includes the variables of value added tax (VAT) number, industrial classification, industrial code, industry name, industry address, contact phone number, main products, raw materials, industry registry, and corporation registry. The seven groups are the asbestos-cement industry, asbestos friction industry, asbestos thermal insulation industry, industries using serpentine, those that applied to use asbestos, those that applied to use asbestos but did not actually use it, and not classified.

Workers in the roster profile of asbestos-related institutions were then linked to the labor insurance database. A total of 566,901 pieces of data were obtained, equaling 183,560 people in this cohort.

\subsection{Airborne Asbestos Concentrations in Asbestos-Related} Industries. The asbestos concentrations in the ambient air in and around different factories were obtained from a literature review. We only reviewed studies conducted by governmental agencies or independent research institutes. During the late 1980s to early 2000s, several studies were conducted to measure the airborne asbestos concentrations via personal sampling and area sampling with regards to the maximum risk groups in Taiwan. The related samples were taken from workers in the four main asbestos-related industries of cement, friction, thermal insulation and textiles, and shipyards. The sampling and analytical methods used for asbestos measurement recommended by the Council of Labor Affairs (CLA) are based on those used by the United States National Institute of Occupational Safety and Health (US-NIOSH) and have been validated by several qualified laboratories in Taiwan $[19,20]$.

2.3. Determination of Individual Cancer Diagnosis. Subjects were followed from 1980 through 2009. To assess the incidence of cancer, the personal identification numbers (IDNs) of these workers were encrypted and identified through linkages with the Taiwan Cancer Registry from 1980 to 2009 with all cancers, including MPM coded by the International Classification of Diseases, 9th Revision (ICD-9), as 163 and lung cancer coded as 162 .

2.4. Statistical Analyses. The National Institute for Occupational Safety and Health (NIOSH) Life Table Analysis System (LTAS) (website link: http://www.cdc.gov/niosh/ltas/) was used to examine cancer incidence. The main analyses used the Taiwanese general population as a reference. In all analyses, 
TABLE 1: Demographic characteristics of the cohort, 1950-2009.

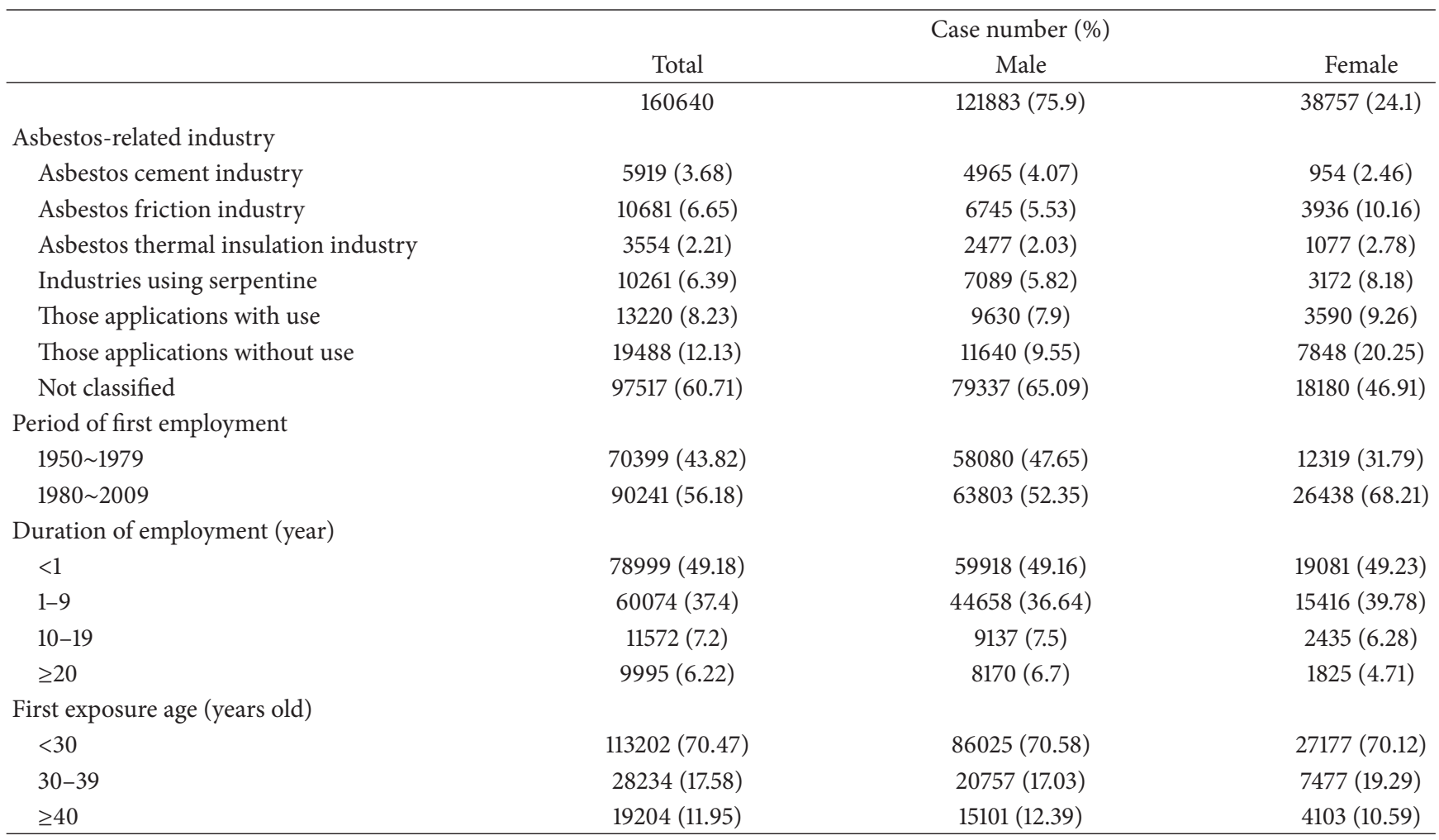

the total person-years at risk (PYAR) of 4,021,078 were stratified by gender and calendar year (in five-year increments). Confidence limits for risk measures were estimated based on a Poisson distribution for the observed outcome, with exact limits for outcomes with 10 or fewer occurrences.

The standardised incidence ratio (SIR) was calculated as the ratio of observed malignancies to the expected number of cases estimated using the Taiwan Cancer Registry file (19802009) published by the Health Promotion Administration, Ministry of Health and Welfare [21]. For the incident case analyses, PYAR began on the date of cohort inclusion (the earliest being: 1 March, 1950) and ended with the earliest index date or 31 December, 2009. To ensure enough latency of MPM after exposure to asbestos, the PYAR includes only the first employment before 1989 of people in the profile, with follow-up of the incident cases until 2009.

In this cohort, the first employee in the profile was employed from 1 March, 1950. We summed up the total coverage time of labor insurance as the duration of employment and further assumed that it could be used as a proxy of the amount of exposure to asbestos (subdivided into $<1$ year, 1-10 years, 11-20 years, and >20 years). We also divided the study group into two categories: those with first employment before 1979 as early employment category and those from 1980 to 2009 as the late employment category, to ensure that it was possible to take account of an adequate latency period of 30 years in the early employment category. To address differences in the duration of employment and first period of employment, the male duration-specific and employment-period-specific SIR of mesothelioma were examined using LTAS.

\section{Results}

3.1. Descriptive Statistics. There were a total of 160,640 workers in asbestos-related factories available for study, for a total of 4,021,078 PYAR. Three-quarters of these are male, and most were employed in the related factories for less than one year $(49.18 \%)$, and more than $70 \%$ started this working in asbestos-related factories at less than 30 years old (Table 1). The late employment category accounted for $56.18 \%$ of the total, with the early employment category accounting for the remaining $43.82 \%$. Most were employed in the asbestosrelated factories in the "not classified" category $(60.71 \%)$, followed by "those that applied to use asbestos but did not actually use it" (12.13\%), "those that applied to use asbestos $(8.23 \%)$, and "asbestos friction industry" (6.65\%).

3.2. Cause-Specific Incidence Analysis. A total of 6,544 incidences of cancer were observed in the male cohort, and this was not above expectations (SIR $=0.48,95 \%$ CI 0.47 to 0.49 ) (Table 2). Seventeen incident cases of MPM were observed, which was above expectations in a statistically significant manner ( $\mathrm{SIR}=2.65,95 \% \mathrm{CI} 1.54$ to 4.25 ). However, apart from MPM the SIRs of most of the other cancers were significantly below expectations (Table 2). Among the female workers, there were 1,894 incidences of cancer (SIR $=0.80$, 95\% CI 0.77 to 0.84$)$. An increased risk of cervical cancer 
TABLE 2: Observed and expected numbers and standardized incidence ratios for cancers among the male and female workers employed in asbestos-related factories.

\begin{tabular}{|c|c|c|c|c|c|c|}
\hline \multirow{2}{*}{ Cancer type } & \multicolumn{3}{|c|}{ Males } & \multicolumn{3}{|c|}{ Females } \\
\hline & Obs. N.O. & Exp. N.O. & $\operatorname{SIR}(95 \% \mathrm{CI})$ & Obs. N.O. & Exp. N.O. & SIR (95\% CI) \\
\hline All cancers & 6544 & 13731.1 & $0.48^{* *}(0.47-0.49)$ & 1894 & 2357.8 & $0.80^{* *}(0.77-0.84)$ \\
\hline Lip, oral cavity, and pharynx & 726 & 1206.1 & $0.60^{* *}(0.56-0.65)$ & 20 & 27.62 & $0.72(0.44-1.12)$ \\
\hline Major salivary glands & 26 & 29.58 & $0.88(0.57-1.29)$ & 6 & 5.79 & $1.04(0.38-2.25)$ \\
\hline Nasopharynx & 363 & 439.58 & $0.83^{* *}(0.74-0.92)$ & 43 & 39.62 & $1.09(0.79-1.46)$ \\
\hline Esophagus & 241 & 378.2 & $0.64^{* *}(0.56-0.72)$ & 5 & 5.62 & $0.89(0.29-2.08)$ \\
\hline Stomach & 409 & 591.48 & $0.69^{* *}(0.63-0.76)$ & 58 & 76.96 & $0.75^{*}(0.57-0.97)$ \\
\hline Colon, rectum, and anus & 872 & 5186.73 & $0.17^{* *}(0.16-0.18)$ & 147 & 623.28 & $0.24^{* *}(0.20-0.28)$ \\
\hline Liver and intrahepatic bile ducts & 1280 & 1971.02 & $0.65^{* *}(0.61-0.69)$ & 120 & 143.87 & $0.83^{*}(0.69-1.00)$ \\
\hline Gall bladder and extrahepatic bile ducts & 45 & 87.53 & $0.51^{* *}(0.37-0.69)$ & 9 & 16.64 & $0.54(0.25-1.03)$ \\
\hline Pancreas & 104 & 167.71 & $0.62^{* *}(0.51-0.75)$ & 19 & 23.64 & $0.80(0.48-1.25)$ \\
\hline Nose, middle ear, and sinuses & 18 & 34.84 & $0.52^{* *}(0.31-0.82)$ & 1 & 4.14 & $0.24(0.01-1.35)$ \\
\hline Larynx & 86 & 139.96 & $0.61^{* *}(0.49-0.76)$ & 3 & 1.77 & $1.69(0.35-4.95)$ \\
\hline Trachea, bronchus, and lung & 758 & 1222.97 & $0.62^{* *}(0.58-0.67)$ & 123 & 144.80 & $0.85(0.71-1.01)$ \\
\hline Retroperitoneum & 6 & 13.99 & $0.43^{*}(0.16-0.93)$ & 4 & 3.95 & $1.01(0.28-2.60)$ \\
\hline Pleura (malignant mesothelioma) & 17 & 6.41 & $2.65^{* *}(1.54-4.25)$ & 1 & 0.60 & $1.67(0.04-9.29)$ \\
\hline Bone and articular cartilage & 15 & 19.54 & $0.77(0.43-1.27)$ & 2 & 4.41 & $0.45(0.05-1.64)$ \\
\hline Skin & 205 & 249.04 & $0.82^{* *}(0.71-0.94)$ & 43 & 44.04 & $0.98(0.71-1.32)$ \\
\hline Female breast & - & - & - & 494 & 493.63 & $1.00(0.91-1.09)$ \\
\hline Uterus and corpus uteri & - & - & - & 78 & 73.51 & $1.06(0.84-1.32)$ \\
\hline Cervix & - & - & - & 412 & 238.08 & $1.73^{* *}(1.57-1.91)$ \\
\hline Adnexa (including ovary) & - & - & - & 53 & 67.28 & $0.79(0.59-1.03)$ \\
\hline Prostate & 307 & 459.99 & $0.67^{* *}(0.59-0.75)$ & - & - & - \\
\hline Bladder & 234 & 310.72 & $0.75^{* *}(0.66-0.86)$ & 19 & 26.25 & $0.72(0.44-1.13)$ \\
\hline Kidney & 96 & 118.19 & $0.81^{*}(0.66-0.99)$ & 11 & 26.77 & $0.41^{* *}(0.20-0.74)$ \\
\hline Renal pelvis and ureter & 80 & 114.29 & $0.70^{* *}(0.56-0.87)$ & 21 & 14.77 & $1.42(0.88-2.17)$ \\
\hline Brain & 60 & 86.82 & $0.69^{* *}(0.53-0.89)$ & 15 & 16.10 & $0.93(0.52-1.54)$ \\
\hline Thyroid gland & 76 & 91.61 & $0.83(0.65-1.04)$ & 91 & 88.98 & $1.02(0.82-1.26)$ \\
\hline Hodgkin lymphoma & 146 & 233.45 & $0.63^{* *}(0.53-0.74)$ & 3 & 2.27 & $1.32(0.27-3.87)$ \\
\hline Non-Hodgkin lymphoma & 6 & 12.96 & $0.46(0.17-1.01)$ & 27 & 41.66 & $0.65^{*}(0.43-0.94)$ \\
\hline Leukemia & 118 & 165.06 & $0.71^{* *}(0.59-0.86)$ & 22 & 30.13 & $0.73(0.46-1.11)$ \\
\hline Others & 250 & 393.35 & $0.64^{* *}(0.56-0.72)$ & 44 & 71.68 & $0.61^{* *}(0.45-0.82)$ \\
\hline
\end{tabular}

${ }^{* *} P<0.01,{ }^{*} P<0.05$. Obs. N.O.: observed number. Exp. N.O.: expected number; $95 \%$ CI: 95\% confidence interval.

was observed, with SIR $=1.73$ (95\% CI 1.57 to $1.91, n=412$ ). The incidences of Hodgkin's lymphoma (SIR $=1.32,95 \%$ CI 0.27 to $3.87, n=3$ ) and MPM (SIR $=1.67,95 \%$ CI 0.04 to $9.29, n=1$ ) both exceeded expectations, but since these results were only based on a few cases, they did not reach statistical significance. Other cancers with slightly higher incidence than expected (although statistically insignificant) included cancer of the major salivary gland (SIR $=1.04,95 \%$ CI 0.38 to 2.25 ), nasopharyngeal cancer (SIR $=1.09,95 \%$ CI 0.79 to 1.46 ), laryngeal cancer ( $\operatorname{SIR}=1.69,95 \%$ CI 0.35 to 4.95 ), endometrial cancer ( $\mathrm{SIR}=1.06,95 \% \mathrm{CI} 0.84$ to 1.32 ), urothelial cancer (SIR $=1.42,95 \%$ CI 0.88 to 2.17 ), and thyroid cancer $(\mathrm{SIR}=1.32,95 \% \mathrm{CI} 0.27$ to 3.87$)$.

Table 3 shows the risks of MPM by period of first employment and time since first employment. The male workers employed before 1979 had a much higher incidence of MPM (SIR: 3.68, 95\% CI: 2.10 to 5.98 ) compared to those employed after 1979 (SIR: 0.62, 95\% CI: 0.00 to 3.48). No incident case of MPM was found before 20 years since first employment. In the early employment category (1950-1979), there was a clear trend that the longer the latency, the more significant the risk: five incident cases of MPM were observed 20 to 30 years since first employment $(\mathrm{SIR}=3.65,95 \% \mathrm{CI}$ : 1.19 to 8.52 ), and 11 cases were observed 30 years since first employment (SIR $=4.52$, 95\% CI: 2.25 to 8.09 ). As shown in Table 4 , the highest incidence of cancer was observed among male workers employed for more than 20 years $(\mathrm{SIR}=5.78$, 95\% CI: 1.19 to $16.89, n=3$ ). Nevertheless, the risk of MPM was also very high among male workers employed for only 1 to 10 years and diagnosed more than 30 years since first employment ( $\mathrm{SIR}=5.25,95 \% \mathrm{CI}: 1.70$ to $12.24, n=5$ ). For male workers employed less than 1 year, the overall SIR was 2.61 (95\% CI: 1.05 to 5.39), with all cases observed having more than 20 years of latency. 


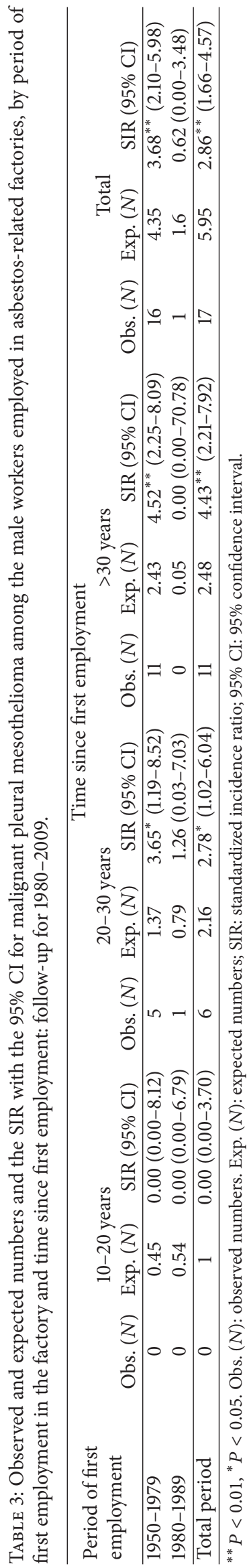




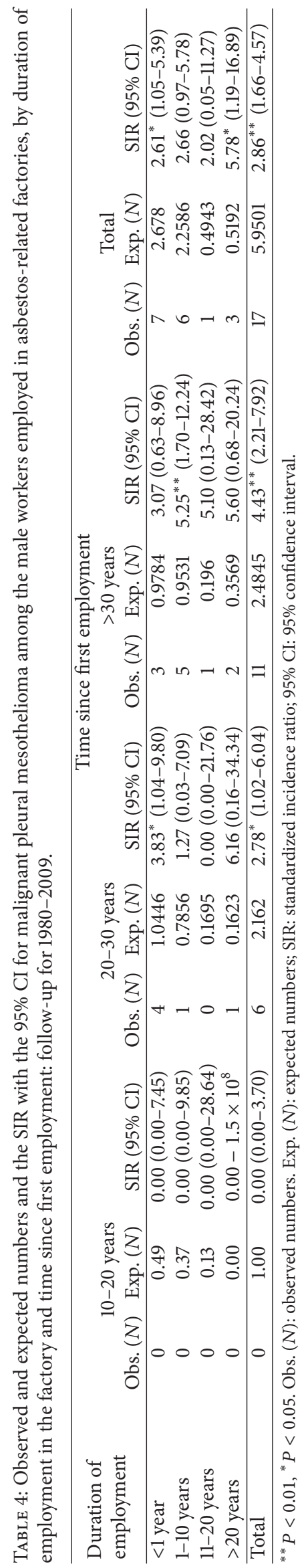


TABLE 5: Characteristics of 17 male cases of MPM employed in asbestos-related factories.

\begin{tabular}{lc}
\hline Characteristics & Percentage (\%) \\
\hline Histology (ICD-O) & \\
Mesothelioma, malignant, NOS (9050/3) & 64.7 \\
Fibrous mesothelioma, malignant (9051/3) & 11.8 \\
$\quad$ Epithelioid mesothelioma, malignant (9052/3) & 23.5 \\
Period of cancer diagnosis & \\
$\quad$ 1980-1999 & 11.8 \\
2000-2009 & 88.2 \\
\hline $\begin{array}{l}\text { Other characteristics } \\
\text { Age at first employment }\end{array}$ & Median (range), \\
Age at cancer diagnosis & 63 (38-74) \\
Latency (time since first employment to cancer & $33.2(22.7-56.4)$ \\
diagnosis) & 1.7 (0.1-30) \\
Duration of employment & \\
* Coded by International Classification of Diseases for Oncology- (ICD-O-) \\
3rd ed., published by WHO Library Cataloguing-in-Publication Data, 2000, \\
reprinted in 2005.
\end{tabular}

The characteristics of seventeen cases of male MPM were shown in Table 5. All of them had histological evidence of MM. The median age at cancer diagnosis was 63 years ranging from 38 to 74 . The median latency of MPM was 33.2 years, and all of the patients developed MPM after 20 years. The median age at first employment was 25 years, the youngest one starting his work from 15 years of age. The median duration of employment was 1.7 years with a wide range from 0.1 years to 30 years. The majority (88\%) of MPM cases were diagnosed after 2000 . Most (16 cases) of them were first employed before 1979, which was classified as the early period in this study. 16 cases were employed in the "not classified" category, and the other was in the industry of insulation.

\subsection{Airborne Asbestos Concentration in Asbestos-Related} Industries. A review of the literature showed that the airborne asbestos concentration varied significantly, depending on the industries examined and when the study was conducted. Current data showed that the maximal airborne asbestos concentration was associated with the asbestos friction industry, at a level of 24.88 fibres $/ \mathrm{mL}$ after industrial hygiene improvement. Although a few studies found very different results, the airborne asbestos concentration for all industries studied ranged from 2.08 to 6.25 on average, exceeding the permissible exposure level (PEL) of $1 \mathrm{fibre} / \mathrm{mL}$ in 2006 , now reduced to $0.15 \mathrm{fibre} / \mathrm{mL}$, as announced by the Taiwan EPA (see Supplementary Table 1 in Supplementary Material available online at http://dx.doi.org/10.1155/2015/678598). Both the total number of asbestos-related factories and the number of workers directly exposed in them fell dramatically to about one-fourth to one-third from 1987 to 2000, especially in textile and ground tile factories, in which the use of asbestos was banned by the Taiwan EPA (Supplementary Table 2).

\section{Discussion}

To the best of our knowledge, this is the first retrospective cohort study to explore cancers risk among employees nationwide asbestos-related industries. The cohort started as early as 1950 when the Bureau of Labour Insurance was just established in Taiwan. The highest risk of MPM was observed in workers employed earlier (before 1979) and who had been employed in such factories for more than 20 years. To some extent, these results corroborate an earlier model showing that mesothelioma risk is determined mainly by the time since first employment and minimal duration of employment is sufficient for causing MM given adequate latency [22].

No increase in overall cancer incidence was found in our cohort of workers in asbestos-related factories compared to the general population. In 1974, McMichael coined the term healthy worker effect (HWE) to describe a phenomenon in which more vigorous occupations had a relatively lower mortality rate when compared with the death rate in occupations of an easier character, or among the unemployed [23]. A year later, Goldsmith [24] pointed out that most industrially employed cohorts should be expected to have better life expectancy than unemployed persons. These phenomena are clearly seen in the findings of the current study.

Some industries, which applied for asbestos use but actually did not use it according to the report system of the Taiwan EPA, were included in our nationwide asbestos industries. Thus, a possible dilution of cancer risk in the whole asbestosrelated occupational cohort with heterogeneous exposure levels would be likely to cause substantial underestimation of risk of all cancers (Table 2 ).

Cigarette smoking is a well-established risk factor of developing lung cancer [25]. Previous surveys revealed that the male working population covered by Taiwanese Labour Insurance had a prevalence of cigarette smoking of $48 \%$ in 1997 [26], which was lower than 55-60\% in the male general population during 1976-1996 [26]. Environmental tobacco smoking (ETS) is also a workplace respiratory carcinogen, and its relative risk of developing lung cancer is estimated to be 3.0 among men [27]. A national workplace smoking survey [27] in 2004 showed that $28.7 \%$ of male workers in the manufacturing industries (the majority of asbestosrelated factories belonged to this type of industries) reported exposure to ETS, which was lower than that of all male workers in Taiwan (33.4\%) [28]. Britain estimate of population attributable fraction (PAF) of occupational asbestos exposure to lung cancer in men was around 9\% [29], which implies occupational asbestos may contribute only a minor role compared with smoking. Therefore, using the Taiwanese general population as the reference, significantly decreased risk of lung cancer among workers in the asbestos-related industries might be explained, or at least partially, by healthy worker effect and possibly lower prevalence of smoking habits as well as secondary smoking.

In addition to MPM and lung cancer, asbestos may also be associated with increased risk of laryngeal, pharyngeal, and oral cavity cancers, as well as cancers of GI tract and colorectum [30]. Other malignancies that have been linked to asbestos, albeit inconclusively, include cervical and prostate 
cancer [31], and some studies have even reported a greater incident risk of brain cancer and testis cancer among male workers employed in asbestos-cement factories [22]. In our study, the SIR of cervical cancer was statistically significantly higher among female workers. This association, however, was not consistent when classified by period of first employment and time since first employment, and thus a causal association for an increased risk of cervical cancer among women exposed to asbestos is less likely. However, more work is required to confirm or refute this statistical association.

Most related studies exclude workers who were exposed to asbestos for less than one year, while our current work included all workers, no matter how long their period of exposure was. This approach is based on prior knowledge and the special circumstances that apply in Taiwan, as follows: (1) the scientific community is in overwhelming agreement that there is no safe level of exposure to asbestos [31]. Moreover, there is no evidence of a threshold level, below which there is no risk of mesothelioma [32]. Minimal exposure to asbestos with long enough latency will thus lead to mesothelioma, and the risk increases exponentially with time since first exposure after the first 10 to 15 years [1], with the greatest risk with regards to mesothelioma occurring approximately 20-40 years later [33]. (2) In Taiwan small- and mediumsized enterprises were once the major part of the economy, and many workers at these were not enrolled in labor insurance at all or were exposed to substantial amounts of asbestos many years before such insurance was offered. Therefore, eliminating the workers with less than one year insurance from the sample was meaningless with regards to guaranteeing adequate exposure in the current study.

According to the Taiwan Cancer Registry file, 54 incident cases of MPM were diagnosed in 2010 [16]. Since more than $90 \%$ of the cancers were attributable to asbestos in male workers and about one-quarter in female workers [19], we might expect many cases of MPM in the current study. However, in this 29-year cohort, only 17 male incident cases and 1 female incident case were observed. The huge gap between expectations and actual results may be due to the following reasons: (1) the roster profile of asbestos-related facilities provided by the Taiwan EPA may not include all such places, as many factories continued to use asbestos without being registered, due to management decisions. In addition, the employment in such firms might also be underreported, especially early in the study period. (2) Diagnosis of MM was difficult to identify, due to the lack of a specific code in ICD-9 [34]. For example, in ICD-9 MM can be coded as 158.9 for peritoneal cancer, 162.9 for lung cancer, 163.9 for pleural cancer, and 199.1 for cancer of unspecific site. According to previous studies $[20,35,36]$, about $52 \%$ to $67 \%$ of mesothelioma deaths were coded as 199.1. The site-specific ICD-9 codes for MPM of 163 and 158 (peritoneum) capture only a fraction of all MM deaths in the United States, and in a recent study only $13 \%$ of all MM death were coded to ICD-9 163 and 4\% coded to 158 [37]. This coding system thus underestimates the incidence of malignant mesothelioma [38-41]. (3) In Taiwan, a population-based cancer registry was established in 1979 that collected basic information, called the short-form system. After 2002, a long-form system was established to collect more detailed information. In 2003, the Cancer Control Act was passed, in which all hospitals were mandated to submit information about cancer patients with trace-back procedure [21], which led to a marked improvement in the quality of cancer registry data [42].

The emergence of asbestos-related diseases has been observed in Taiwanese workers with occupational exposure to asbestos, including (1) pleural plaque in a female worker in asbestos mining in eastern Taiwan [43], (2) pulmonary fibrosis identified among male workers in Taiwanese jade manufacturing factories [12], and 10 patients of asbestosis among male shipbreaking workers [15]. A few cases of MPM in Taiwan have been reported with significant occupational exposure to asbestos, including pipefitter in a shipyard [44] and a 39 year-old carpenter with probable bystander exposure in construction industry [45]. This study with adequate person-years of follow up to detect the risk of MPM corroborated the causal association between occupational asbestos exposure and MPM.

To set up epidemiological surveillance of the effects of asbestos exposure on the French population health, the National Mesothelioma Surveillance Program was established in 1998 in France based on continual following up of MPM [46]. Koreans have begun a nationwide MM surveillance system since 2000 to monitor pathologically confirmed cases and their exposure histories by interview [47]. A clinicopathological correlation study on 1,445 MM cases revealed that the largest number of cases was from shipyard, service in the Navy, the construction industry, and the insulation industry [48]. We also found that patients with MPM were workers employed in the shipyards and insulation industry. Thus, we recommended that MM surveillance system should be established in Taiwan as early as possible for (1) collecting occupational and environmental exposure to asbestos; (2) monitoring trends of epidemiological data; and (3) identifying sentinel cases in high-risk industries for early detection of asbestos-related diseases.

4.1. Limitations. There are several limitations in this study that suggest directions for future research, as follows. First, while there were various exposure levels at different factories, the current study lacks a detailed exposure assessment. This is because we did not have data regarding the type of asbestos used in each factory, and measurements of the airborne asbestos dust concentration were based on a literature review. Some studies in the 1980 s can provide a rough picture of asbestos exposure in the past. For example, a general survey of 33 registered asbestos factories in Taiwan during 19861987 found that all of them employed less than 100 workers, for the average duration of 8.1 years, and thus had a high turnover rate, with a low awareness of the related hazards, and only about $42 \%$ of them provided regular medical screening [49]. According to an industrial hygiene survey, chrysotile was in use in the majority of the factories $(31 / 33,94 \%)$, one factory used amosite, and a mixture of chrysotile, amosite, and crocidolite was used in another factory [49]. Nationwide determinations of the airborne asbestos concentration of asbestos-related factories vary in different studies conducted 
in different periods. Chang et al. [50] used data from 1987 to 1988 and undertook a thorough survey of the ambient asbestos concentrations in the four main asbestos-related industries of cement, friction thermal insulation, and textiles in Taiwan. The concentration of airborne asbestos was the highest, at $6.25 \mathrm{fibres} / \mathrm{mL}$, in asbestos textile factories, followed by the friction factories and insulation factories, with 3.57 fibres $/ \mathrm{mL}$ and 2.23 fibres $/ \mathrm{mL}$, respectively. Some tasks, such as grinding and drilling in the friction industry, had highest concentrations of 10 fibres/mL $[49,51]$. While these studies provide valuable information with regards to exposure data, they cover a very broad range of contexts and thus the results are of doubtful generalizability. Second, we did not have data on cigarette smoking among the workers in asbestos-related factories. While smoking is a wellestablished risk factor associated with lung cancer, it has little or no effect on the incidence rates of mesothelioma [52]. In addition, our results showed no increased risk of lung cancer among the workers. Third, historical rates of asbestos use are associated with a greater risk of mesothelioma approximately 20-40 years later [25]. In this 29-year follow-up study our observation span was limited from 1980 to 2009 , which might not be enough due to the long latency of mesothelioma, and more incident cases of MPM are expected after 2009. Further observations are thus essential.

\section{Conclusions}

In this study a higher risk of MPM was found among male workers employed in the early period, before 1979, especially those employed for more than 20 years. Our findings support the view that minimal exposure to asbestos with long latency is enough to increase the risk of MPM.

\section{Conflict of Interests}

The authors declare that there is no conflict of interests regarding the publication of this paper.

\section{Acknowledgments}

The authors acknowledge Dr. Chi-Shien Young and Dr. Chih-Hong Pan of the Institute of Occupational Safety and Health for their kind help in data collection. This study was supported by the Institute of Occupational Health and Safety (Grant no. IOSH-102-M3044) and the National Health Research Institutes (NHRI) intramural project EO-102-PP04 and the Headquarters of University Advancement at the National Cheng Kung University, which is sponsored by the Ministry of Education, Taiwan.

\section{References}

[1] E. Jamrozik, N. de Klerk, and A. W. Musk, "Asbestos-related disease," Internal Medicine Journal, vol. 41, no. 5, pp. 372-380, 2011.

[2] C. Ramazzini and M. Soffritti, "Asbestos is still with us: repeat call for a universal ban," American Journal of Industrial Medicine, vol. 54, no. 2, pp. 168-173, 2011.
[3] K. Straif, L. Benbrahim-Tallaa, R. Baan et al., "A review of human carcinogens-part C: metals, arsenic, dusts, and fibres," The Lancet Oncology, vol. 10, no. 5, pp. 453-454, 2009.

[4] M. Clements, G. Berry, J. Shi, S. Ware, D. Yates, and A. Johnson, "Projected mesothelioma incidence in men in New South Wales," Occupational and Environmental Medicine, vol. 64, no. 11, pp. 747-752, 2007.

[5] S. C. Kao, G. Reid, K. Lee, J. Vardy, S. Clarke, and N. Van Zandwijk, "Malignant mesothelioma," Internal Medicine Journal, vol. 40, no. 11, pp. 742-750, 2010.

[6] World Health Organization, "Asbestos: elimination of asbestosrelated diseases," Media Center: WHO Fact Sheet no. 343, World Health Organization, 2014, http://www.who.int/mediacentre/ factsheets/fs343/en/.

[7] M. R. Becklake, E. Bagatin, and J. A. Neder, "Asbestos-related diseases of the lungs and pleura: uses, trends and management over the last century," International Journal of Tuberculosis and Lung Disease, vol. 11, no. 4, pp. 356-369, 2007.

[8] T. Brown, A. Darnton, L. Fortunato, and L. Rushton, "Occupational cancer in Britain-respiratory cancer sites: larynx, lung and mesothelioma," British Journal of Cancer, vol. 107, no. 1, pp. S56-S70, 2012.

[9] A. T. Sporn and V. L. Roggli, "Mesothelioma," in Pathology of Asbestos-Associated Diseases, A. T. Sporn and V. L. Roggli, Eds., pp. 104-168, Springer, New York, NY, USA, 2nd edition, 2004.

[10] J. C. Wagner, C. A. Sleggs, and P. Marchand, "Diffuse pleural mesothelioma and asbestos exposure in the North Western Cape Province," British Journal of Industrial Medicine, vol. 17, pp. 260-271, 1960.

[11] D. W. Henderson, J. Rantanen, S. Barnhart et al., "Asbestos, asbestosis, and cancer: the Helsinki criteria for diagnosis and attribution," Scandinavian Journal of Work, Environment and Health, vol. 23, no. 4, pp. 311-316, 1997.

[12] H.-Y. Yang, R.-H. Shie, and P.-C. Chen, "Carving of nonasbestiform tremolite and the risk of lung cancer: a followup mortality study in a historical nephrite processing cohort," Occupational and Environmental Medicine, vol. 70, no. 12, pp. 852-857, 2013.

[13] T. Robin, Asbestos on Ships-How to Manage It Safely, 2014, http://www.lr.org/en/_images/213-35794_AsbestosGuide2013_ tcm155-247011.pdf.

[14] Y.-K. Liu, G.-Y. Yang, T.-N. Wu, R. S. Lin, and F.-C. Sung, "Mortality among former shipbreaking workers-a 13-year retrospective follow-up study in Taiwan," Journal of Occupational Health, vol. 45, no. 1, pp. 36-42, 2003.

[15] W.-T. Wu, Y.-H. Lu, Y.-J. Lin et al., "Mortality among shipbreaking workers in Taiwan-a retrospective cohort study from 1985 to 2008," The American Journal of Industrial Medicine, vol. 56, no. 6, pp. 701-708, 2013.

[16] W. T. Wu, Y. J. Lin, H. S. Shiue et al., "Cancer incidence of Taiwanese shipbreaking workers who have been potentially exposed to asbestos," Environmental Research, vol. 132, pp. 370378, 2014.

[17] L. Kazan-Allen, Current asbestos bans and restrictions, 2014, http://ibasecretariat.org/alpha_ban_list.php.

[18] Taiwan Environmental Protection Administration, EPA Announces Schedule for Full Ban on Asbestos, The Environmental Protection Administration, Taiwan, 2012, http:// www.epa.gov.tw/FileLink/FileHandler.ashx?file=15632.

[19] M. Wei and P. Wei, "Occupational risk factors for selected cancers," The American Journal of Public Health, vol. 94, no. 7, p. 1078, 2004. 
[20] R. J. Lewis, J. F. Gamble, and G. Jorgensen, "Mortality among three refinery/petrochemical plant cohorts. I. 1970 to 1982 active/terminated workers," Journal of Occupational and Environmental Medicine, vol. 42, no. 7, pp. 721-729, 2000.

[21] Tawian Cancer Registry, Cancer Registry Annual Report, Taiwan Bureau of Health Promotion, Department of Health, 2010.

[22] B. Ulvestad, K. Kjærheim, J. I. Martinsen et al., "Cancer incidence among workers in the asbestos-cement producing industry in Norway," Scandinavian Journal of Work, Environment \& Health, vol. 28, no. 6, pp. 411-417, 2002.

[23] A. J. McMichael, R. Spirtas, and L. L. Kupper, "An epidemiologic study of mortality within a cohort of rubber workers, 1964-72," Journal of Occupational Medicine, vol. 16, no. 7, pp. 458-464, 1974.

[24] J. R. Goldsmith, "What do we expect from an occupational cohort?" Journal of Occupational Medicine, vol. 17, no. 2, pp. 126128, 1975.

[25] D. M. Parkin, "Tobacco-attributable cancer burden in the UK in 2010," British Journal of Cancer, vol. 105, no. 2, pp. S6-S13, 2011.

[26] Taiwan Provincial Tobacco and Liquor Monopoly Bureau, Tobacco and Liquor Consumption Surveys for Taiwan Area, Taiwan Provincial Tobacco and Liquor Monopoly Bureau, Taiwan, China, 1966, 1976, 1986, 1996 (Chinese).

[27] M. Nurminen and A. Karjalainen, "Epidemiologic estimate of the proportion of fatalities related to occupational factors in Finland," Scandinavian Journal of Work, Environment and Health, vol. 27, no. 3, pp. 161-213, 2001.

[28] Health Promotion Administration, Ministry of Health and Welfare, Taiwan. Report of Investigation on Healthy Working Environment in Taiwan, http://tp2-pp021.24drs.com/Hot News/h_NewsDetailN.aspx?TopIcNo=3985.

[29] B. Ulvestad, K. Kjærheim, J. I. Martinsen, G. Mowe, and A. Andersen, "Cancer incidence among members of the Norwegian trade union of insulation workers," Journal of Occupational and Environmental Medicine, vol. 46, no. 1, pp. 84-89, 2004.

[30] A. Reid, A. Segal, J. S. Heyworth, N. H. de Klerk, and A. W. Musk, "Gynecologic and breast cancers in women after exposure to blue Asbestos at Wittenoom," Cancer Epidemiology, Biomarkers \& Prevention, vol. 18, no. 1, pp. 140-147, 2009.

[31] L. S. Welch, "Asbestos exposure causes mesothelioma, but not this asbestos exposure: an amicus brief to the Michigan supreme court," International Journal of Occupational and Environmental Health, vol. 13, no. 3, pp. 318-327, 2007.

[32] G. Hillerdal, "Mesothelioma: cases associated with nonoccupational and low dose exposures," Occupational and Environmental Medicine, vol. 56, no. 8, pp. 505-513, 1999.

[33] B. W. Robinson, A. W. Musk, and R. A. Lake, "Malignant mesothelioma," The Lancet, vol. 366, no. 9483, pp. 397-408, 2005.

[34] Institute of Occupational Safety and Health, Development of an Occupation Referent Population for Epidemiological Study, Institute of Occupational Safety and Health, Taipei, Taiwan, 1999.

[35] W. W. Huebner, N. C. Wojcik, K. Rosamilia, G. Jorgensen, and C. A. Milano, "Mortality updates (1970-1997) of two refinery/petrochemical plant cohorts at Baton Rouge, Louisiana, and Baytown, Texas," Journal of Occupational and Environmental Medicine, vol. 46, no. 12, pp. 1229-1245, 2004.

[36] W. W. Huebner, N. C. Wojcik, G. Jorgensen, S. P. Marcella, and M. J. Nicolich, "Mortality patterns and trends among 127,266 U.S.-based men in a petroleum company: update 1979-2000,"
Journal of Occupational and Environmental Medicine, vol. 51, no. 11, pp. 1333-1348, 2009.

[37] N. C. Wojcik, A. R. Schnatter, and W. W. Huebner, "Mesothelioma in occupational cohort studies: methodological considerations," Journal of Occupational and Environmental Medicine, vol. 56, no. 1, pp. 47-51, 2014.

[38] R. R. Connelly, R. Spirtas, M. H. Myers, C. L. Percy, and J. F. Fraumeni Jr., "Demographic patterns for mesothelioma in the United States," Journal of the National Cancer Institute, vol. 78, no. 6, pp. 1053-1060, 1987.

[39] L. K. Davis, T. R. Martin, and B. Kligler, "Use of death certificates for mesothelioma surveillance," Public Health Reports, vol. 107, no. 4, pp. 481-483, 1992.

[40] D. R. Camidge, D. L. Stockton, and M. Bain, "Factors affecting the mesothelioma detection rate within national and international epidemiological studies: insights from Scottish linked cancer registry-mortality data," British Journal of Cancer, vol. 95, no. 5, pp. 649-652, 2006.

[41] Y. Iwatsubo, M. Matrat, E. Michel et al., "Estimation of the incidence of pleural mesothelioma according to death certificates in France," The American Journal of Industrial Medicine, vol. 42, no. 3, pp. 188-199, 2002.

[42] C. J. Chiang, Y. C. Chen, C. J. Chen et al., "Cancer trends in Taiwan," Japanese Journal of Clinical Oncology, vol. 40, no. 10, pp. 897-904, 2010.

[43] H.-Y. Yang, J.-D. Wang, P.-C. Chen, and J.-J. Lee, "Pleural plaque related to asbestos mining in Taiwan," Journal of the Formosan Medical Association, vol. 109, no. 12, pp. 928-933, 2010.

[44] T. H. Wu, C. H. Chen, J. Y. Wu et al., "Malignant mesothelioma from occupational asbestos exposure: a case report," Formosan Journal of Medicine, vol. 13, pp. 461-470, 2009 (Chinese).

[45] L. W. Wu, S. T. Chiang, C. C. Wang et al., "Suspect asbestos related malignant mesothelioma: a case report and review of literature," Chinese Journal of Occupational Medicine, vol. 18, pp. 1-6, 2011 (Chinese).

[46] M. Goldberg, E. Imbernon, P. Rolland et al., "The French national mesothelioma surveillance program," Occupational and Environmental Medicine, vol. 63, no. 6, pp. 390-395, 2006.

[47] H.-E. Lee and H. R. Kim, "Occupational respiratory cancer in Korea," Journal of Korean Medical Science, vol. 25, pp. S94-S98, 2010.

[48] V. L. Roggli, A. Sharma, K. J. Butnor, T. Sporn, and R. T. Vollmer, "Malignant mesothelioma and occupational exposure to asbestos: a clinicopathological correlation of 1445 cases," Ultrastructural Pathology, vol. 26, no. 2, pp. 55-65, 2002.

[49] C. R. Chen, H. Y. Chang, J. Suo, and J. D. Wang, "Occupational exposure and respiratory morbidity among asbestos workers in Taiwan," Journal of the Formosan Medical Association, vol. 91, no. 12, pp. 1138-1142, 1992.

[50] H. Y. Chang, J. D. Wang, J. W. Chang et al., "Airborne asbestos concentration in asbestos-related factories in Taiwan," Journal of National Public Health Association, vol. 8, pp. 28-35, 1988.

[51] H.-Y. Chang, C.-R. Chen, and J.-D. Wang, "Risk assessment of lung cancer and mesothelioma in people living near asbestosrelated factories in Taiwan," Archives of Environmental Health, vol. 54, no. 3, pp. 194-201, 1999.

[52] L. M. Lacquet, L. van der Linden, and J. Lepoutre, "Roentgenographic lung changes, asbestosis and mortality in a Belgian asbestos-cement factory," IARC Scientific Publications, no. 30, pp. 783-793, 1980. 


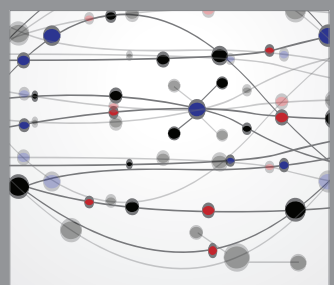

The Scientific World Journal
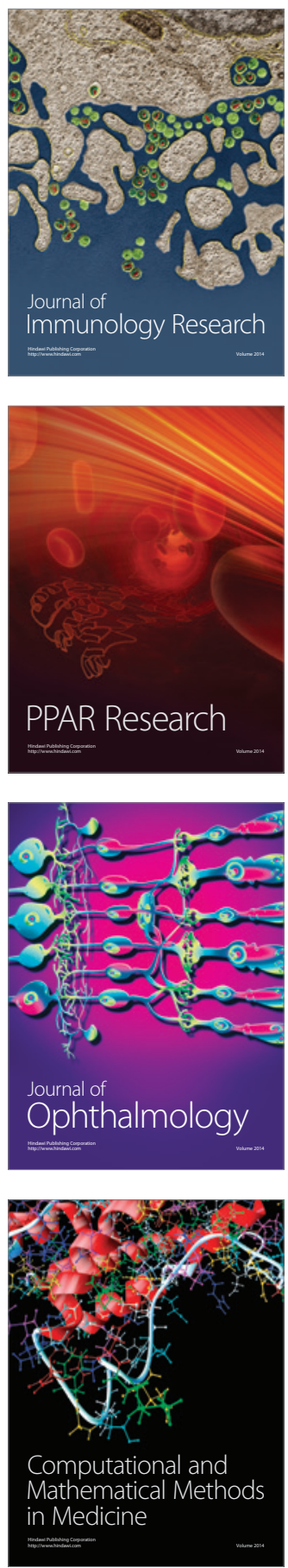

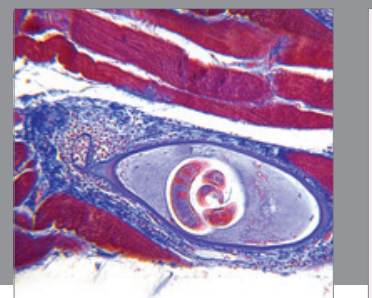

Gastroenterology

Research and Practice
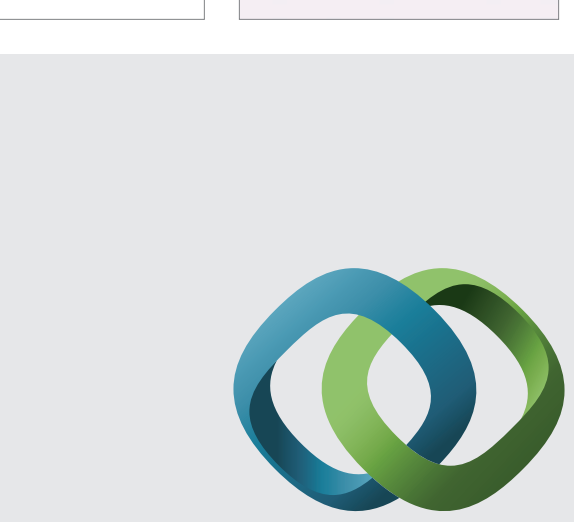

\section{Hindawi}

Submit your manuscripts at

http://www.hindawi.com
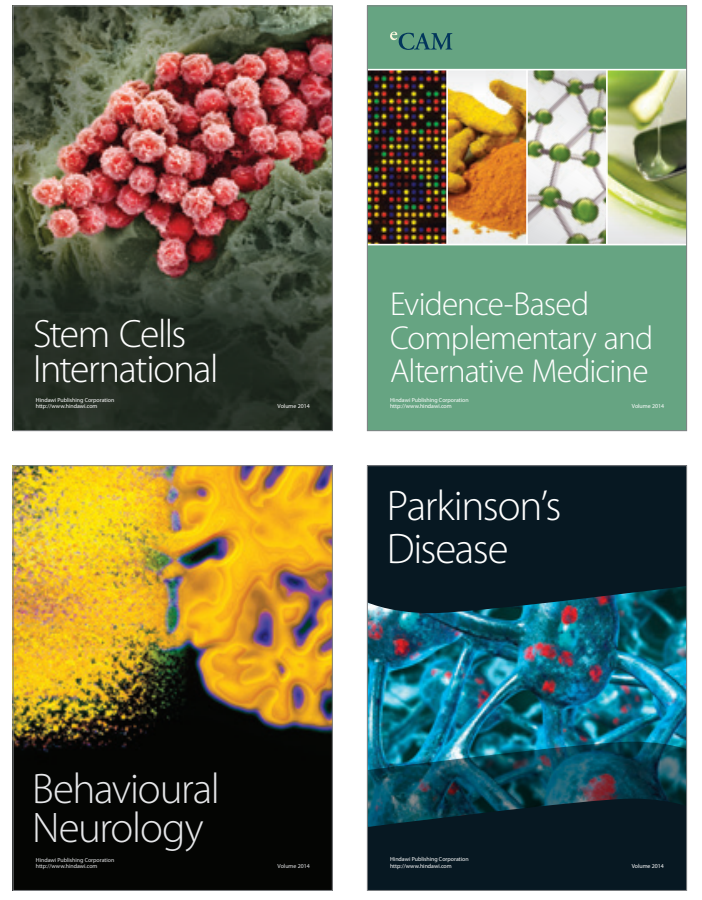
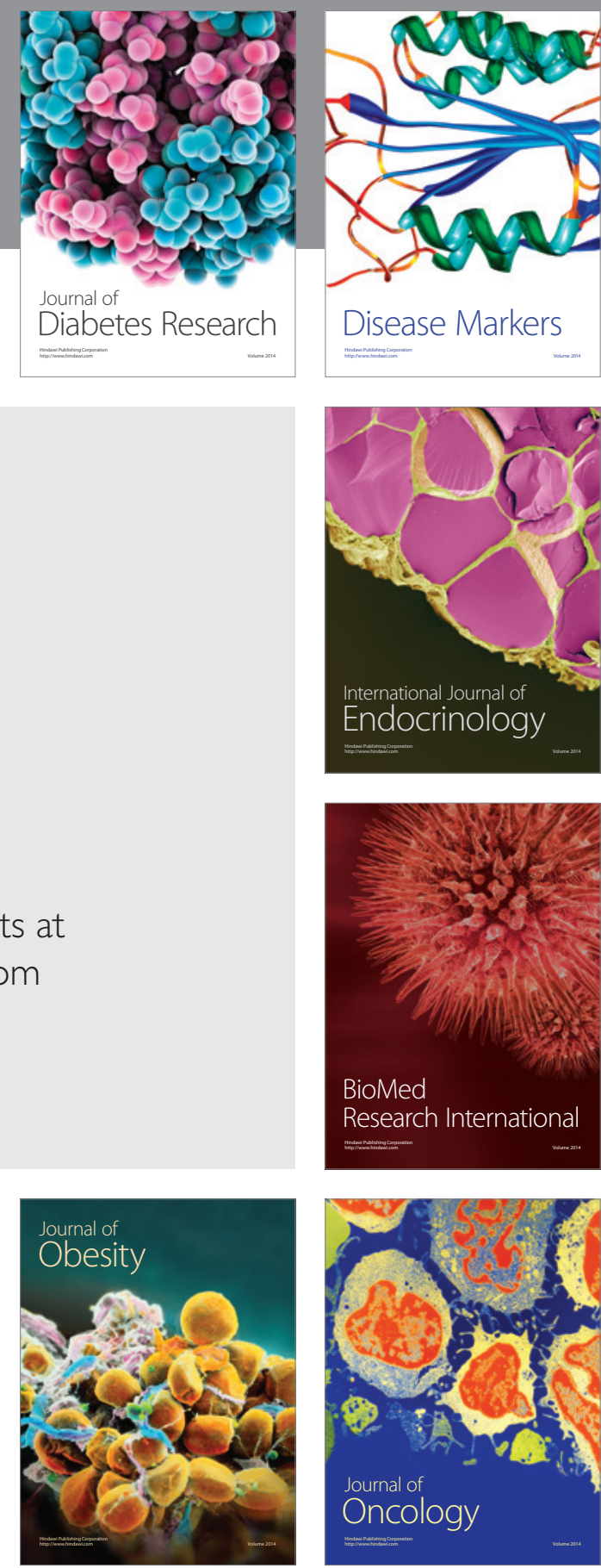

Disease Markers
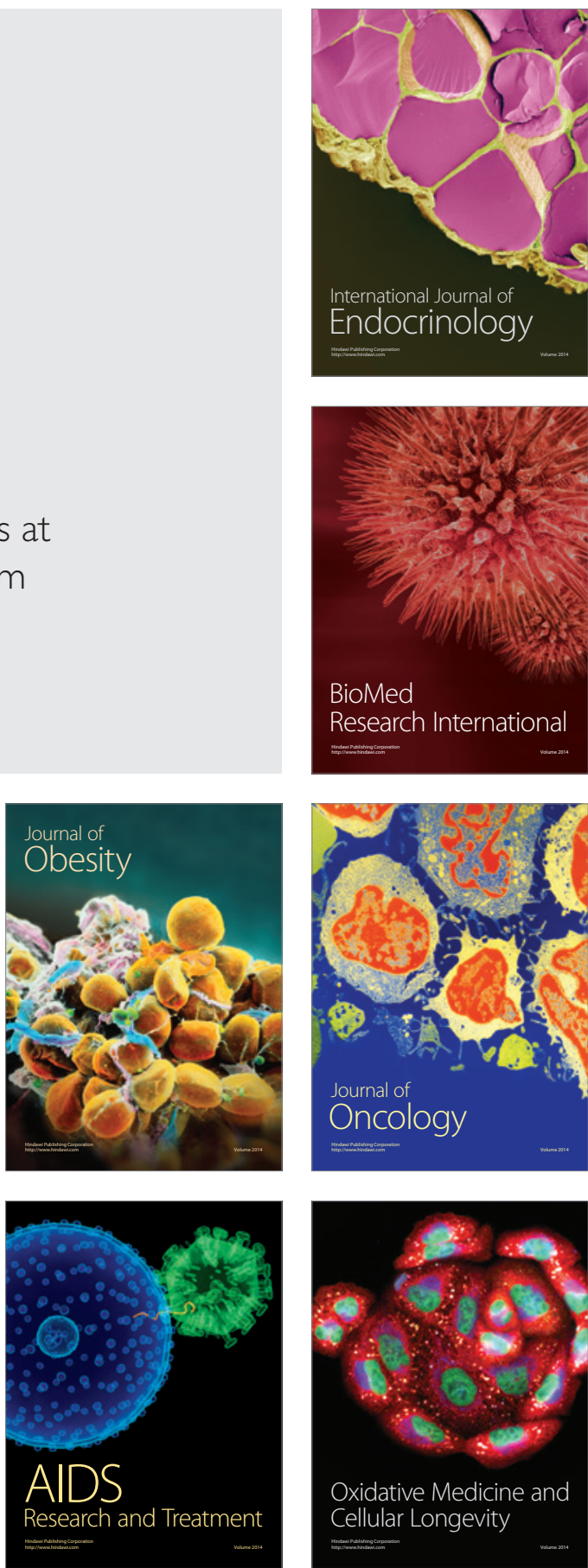